\title{
Ocular-symptoms-related Google Search Trends during the COVID-19 Pandemic in Europe
}

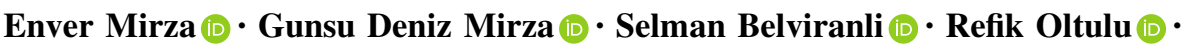 \\ Mehmet Okka $(\mathbb{D}$
}

Received: 19 November 2020/Accepted: 6 March 2021/Published online: 16 March 2021

(C) The Author(s), under exclusive licence to Springer Nature B.V. 2021

\begin{abstract}
Purpose To investigate the correlation between the daily relative search volume (RSV) of keywords related to coronavirus and ocular symptoms, and the numbers of the daily coronavirus disease 2019 (COVID-19) new cases and new deaths in Europe using Google Trends (GT).

Methods The RSVs of the selected keywords related to coronavirus and ocular symptoms between 24 January and 1 June 2020 in the United Kingdom, Spain, Italy, Germany and Turkey were accessed from GT. The numbers of daily COVID-19 new cases and new deaths in the same time interval in the aforementioned countries were compared with the RSVs of the keywords and terms.

Results The United Kingdom, Spain, Italy, Germany, and Turkey were the most affected countries from the COVID-19 pandemic in Europe. In these countries, statistically significant and strong correlations were found between the daily RSVs of most keywords related to coronavirus and ocular symptoms,
\end{abstract}

E. Mirza $(\bowtie) \cdot S$. Belviranli · R. Oltulu · M. Okka Department of Ophthalmology, Meram Faculty of Medicine, Necmettin Erbakan University,

Meram, Konya 42080, Türkiye

e-mail: envermirza@gmail.com

\section{G. D. Mirza}

Clinic of Ophthalmology, Beyhekim State Hospital, Konya, Türkiye and the daily numbers of COVID-19 new cases and new deaths ranging from 0.175 to 0.807 .

Conclusions Ocular symptoms are not the frequent signs of COVID-19, but the ocular surface is a possible route for the transmission of COVID-19. The preliminary outcomes of this study demonstrated that there are significant correlations with the ocular symptoms and COVID-19. The news about the relation of eye and COVID-19 in the mass media may have influenced the Google internet search activity of the public for ocular symptoms.

Keywords COVID-19 - Google Trends · Conjunctivitis · Ocular sign · Internet search activity · Infodemiology

\section{Introduction}

In December 2019, coronavirus disease 2019 (COVID-19) was caused by a new coronavirus had started in Wuhan, China [1]. This new disease spread rapidly all over the world and was declared as a pandemic by the World Health Organization (WHO) on March 11, 2020 [2]. Globally, COVID-19 has caused more than 10 million confirmed cases and more than half a million deaths in about 6 months [3]. In addition, Europe was declared by the WHO as the new epicenter of the COVID-19 pandemic on March 13, 
2020, with the rapid increase of cases [4]. As of June 1, 2020, the most affected countries from the COVID-19 pandemic in Europe with more than 2 million confirmed cases and more than 180000 confirmed deaths were the United Kingdom, Spain, Italy, Germany, and Turkey [3].

According to the current knowledge, it has been informed that COVID-19 is transmitted by close contact, inhalation and the most common initial symptoms of COVID-19 have been reported to be dry cough, dyspnea, fever, and fatigue [5]. Moreover, unlike the symptoms of a common virus infection, conjunctivitis has also been reported in patients with COVID-19 [6-8]. In the case report of Daruich et al., the authors have reported that COVID-19 was suspected in a patient with conjunctivitis and then the diagnosis of COVID-19 was confirmed with positive reverse transcriptase-polymerase chain reaction (RTPCR) from nasopharyngeal swab [6]. Additionally, it has been stated in the mass media that conjunctivitis may also be a symptom of COVID-19 and the ocular surface may be another route in the transmission of COVID-19.

In other respects, internet access and social media usage have increased in the last decade. In order to get information on the new COVID-19 pandemic, the rate of searching for COVID-19 symptoms, diagnosis, and treatment on the internet also increased during this period. Google Search (Google Inc., Mountain View, California) is one of the most popular internet search engines and approximately 2 out of 3 searches are made via Google [9]. It is possible to obtain information about the search rates in a certain region within a certain time interval with the Google Trends (GT) provided by Google [10]. In recent years, researchers have been increasingly using GT for a diversity of health topics with some successful applications in the field of infectious disease surveillance. Indeed, several articles have recently been published evaluating the relationship of public interest to COVID-19 with the internet during the COVID-19 pandemic period [11-15].

Based on this, the aim of this study was to compare the correlations of the search activities for ocularsymptoms-related keywords which were accessed from GT and the numbers of COVID-19 new cases and new deaths in the five most-affected countries of Europe from the COVID-19 pandemic.

\section{Materials and methods}

The article on GT and infodemiology reported by Mavragani and Ochoa guided our study [10]. In brief, after the keyword selection, the keyword is written in the search bar of GT main page. Then, the location, time interval, category, and search type are selected. After that, GT calculates the RSV of the keywords according to the selected types and gives results which can be downloaded in.csv format. Hereunder, the data on the frequencies of the keywords that users search on Google search engine was obtained from GT. GT data does not show the total number of searches for a keyword. Instead, GT organizes search data to represent the popularity (related search volume [RSV]) of a search in a specific time period and geographic location among other searches. Then data points are scaled from 0 to 100 , based on the ratio of a topic to all searches on all topics. The 100 score represents the highest level of RSV a given search can get within a selected location and time frame. In addition, the GT excludes repeated searches from the same person in a short time to prevent selection bias.

According to the data of COVID-19 Situation Report - 133 by WHO, we included the GT data of the United Kingdom, Spain, Italy, Germany, and Turkey in our study which were the five most-affected countries of Europe from the COVID-19 pandemic and also the worldwide data was added (Table 1)[3]. Primarily, we selected some keywords and these keywords included ocular-symptoms-related and/or coronavirus-related keywords such as 'coronavirus eye', 'coronavirus eye symptoms', 'conjunctivitis',

Table 1 The total numbers of confirmed COVID-19 cases and deaths worldwide and 5 countries in Europe according to the Situation Report -133 by World Health Organization

\begin{tabular}{lll}
\hline & $\begin{array}{l}\text { Confirmed } \\
\text { COVID-19 Total } \\
\text { cases }\end{array}$ & $\begin{array}{l}\text { Confirmed } \\
\text { COVID-19 total } \\
\text { deaths }\end{array}$ \\
\hline Worldwide & $6,057,853$ & 371,166 \\
Europe & $2,159,791$ & 180,594 \\
The United Kingdom & 274,766 & 38,489 \\
Spain & 239,801 & 29,045 \\
Italy & 233,019 & 33,415 \\
Germany & 181,815 & 8511 \\
Turkey & 163,942 & 4540 \\
\hline
\end{tabular}


Table 2 The correlation of the RSVs of the keywords with COVID-19 new cases and new deaths worldwide

\begin{tabular}{|c|c|c|c|}
\hline Keywords (Worldwide) & & New cases & New deaths \\
\hline \multirow[t]{2}{*}{ Coronavirus eye } & Correlation coefficient & $0.284 * *$ & $0.504 * *$ \\
\hline & $p$ value & 0.001 & $<0.001$ \\
\hline \multirow[t]{2}{*}{ Coronavirus eye symptoms } & Correlation coefficient & 0.097 & $0.244 * *$ \\
\hline & $p$ value & 0.273 & 0.005 \\
\hline \multirow[t]{2}{*}{ Conjunctivitis } & Correlation coefficient & $-0.707 * *$ & $-0.744 * *$ \\
\hline & $p$ value & $<0.001$ & $<0.001$ \\
\hline \multirow[t]{2}{*}{ Eye infection } & Correlation coefficient & $-0.434 * *$ & $-0.446 * *$ \\
\hline & $p$ value & $<0.001$ & $<0.001$ \\
\hline \multirow[t]{2}{*}{ Red eye } & Correlation coefficient & -0.095 & -0.036 \\
\hline & $p$ value & 0.283 & 0.688 \\
\hline \multirow[t]{2}{*}{ Coronavirus red eye } & Correlation coefficient & $0.345 * *$ & $0.525 * *$ \\
\hline & $p$ value & $<0.001$ & $<0.001$ \\
\hline \multirow[t]{2}{*}{ Pink eye } & Correlation coefficient & $-0.737 * *$ & $-0.556^{* *}$ \\
\hline & $p$ value & $<0.001$ & $<0.001$ \\
\hline \multirow[t]{2}{*}{ Pink eye coronavirus } & Correlation coefficient & $0.439 * *$ & $0.683 * *$ \\
\hline & $p$ value & $<0.001$ & $<0.001$ \\
\hline \multirow[t]{2}{*}{ Pink eye coronavirus symptom } & Correlation coefficient & $0.548 * *$ & $0.706 * *$ \\
\hline & $p$ value & $<0.001$ & $<0.001$ \\
\hline \multirow[t]{2}{*}{ Eye pain coronavirus } & Correlation coefficient & $0.354 * *$ & $0.482 * *$ \\
\hline & $p$ value & $<0.001$ & $<0.001$ \\
\hline \multirow[t]{2}{*}{ Burning eye } & Correlation coefficient & $0.213 *$ & $0.239 * *$ \\
\hline & $p$ value & 0.015 & 0.006 \\
\hline \multirow[t]{2}{*}{ Watery eyes } & Correlation coefficient & $-0.380^{* *}$ & $-0.251^{* *}$ \\
\hline & $p$ value & $<0.001$ & 0.004 \\
\hline \multirow[t]{2}{*}{ Epiphora } & Correlation coefficient & $-0.216^{*}$ & -0.163 \\
\hline & $p$ value & 0.014 & 0.064 \\
\hline \multirow[t]{2}{*}{ Protective face mask } & Correlation coefficient & $0.607 * *$ & $0.791 * *$ \\
\hline & $p$ value & $<0.001$ & $<0.001$ \\
\hline
\end{tabular}

'eye infection', 'red eye', 'burning eye', 'watery eyes', 'epiphora', and 'protective face mask'. Then, we used translations of the aforementioned keywords in Spanish, Italian, German, and Turkish and searched the RSVs of each keyword on GT. Each keyword was entered in the GT main page by using these filters: "all categories" (category); worldwide, the United Kingdom, Spain, Italy, Germany, and Turkey (location) and web search (search type). The first confirmed COVID-19 case was seen on January 24, 2020, in Europe, and on June 1, 2020, many countries have canceled lockdown [16]. Therefore, we selected these dates as the beginning and ending dates of our investigation interval. The use of these keywords is not the same in all countries and they can be used differently. When the main keyword is searched, GT suggests the most related queries or most frequently searched other keywords in the same search session within the same filters to the researchers [10]. Due to these features, we also included some of the suggested keywords of GT and the daily RSV datasets were downloaded [17]. In addition, the confirmed numbers of daily COVID-19 new cases and new deaths between January 24 and June 1, 2020, for the United Kingdom, Spain, Italy, Germany, Turkey, and worldwide were gained from WHO COVID-19 Dashboard [18].

The present study was approved by the Ethical Committee of Necmettin Erbakan University and adhered to the tenets of the Declaration of Helsinki (No.: 2020/2768). Statistical analyses of the data were performed using the SPSS 20.0 software (IBM Corporation, Armonk, NY, US). Continuous variables 
Table 3 The correlation of the RSVs of the keywords with COVID-19 new cases and new deaths in the United Kingdom
** Correlation is significant at the 0.01 level (2-tailed)

*Correlation is significant at the 0.05 level (2-tailed)

Bold results: Statistically significant results

\begin{tabular}{|c|c|c|c|}
\hline Keywords (The United Kingdom) & & New cases & New deaths \\
\hline \multirow[t]{2}{*}{ Coronavirus eye } & Correlation coefficient & $0.512 * *$ & $0.487 * *$ \\
\hline & $p$ value & $<0.001$ & $<0.001$ \\
\hline \multirow[t]{2}{*}{ Coronavirus eye symptoms } & Correlation coefficient & $0.224^{*}$ & 0.113 \\
\hline & $p$ value & 0.010 & 0.199 \\
\hline \multirow[t]{2}{*}{ Conjunctivitis } & Correlation coefficient & $-0.755^{* *}$ & $-0.782^{* *}$ \\
\hline & $p$ value & $<0.001$ & $<0.001$ \\
\hline \multirow[t]{2}{*}{ Eye infection } & Correlation coefficient & $-0.205^{*}$ & $-0.227^{* *}$ \\
\hline & $p$ value & 0.020 & 0.009 \\
\hline \multirow[t]{2}{*}{ Eye infection coronavirus } & Correlation coefficient & $0.344 * *$ & $0.362 * *$ \\
\hline & $p$ value & $<0.001$ & $<0.001$ \\
\hline \multirow[t]{2}{*}{ Red eye } & Correlation coefficient & 0.112 & 0.111 \\
\hline & $p$ value & 0.204 & 0.210 \\
\hline \multirow[t]{2}{*}{ Pink eye } & Correlation coefficient & -0.040 & -0.095 \\
\hline & $p$ value & 0.654 & 0.280 \\
\hline \multirow[t]{2}{*}{ Pink eye coronavirus } & Correlation coefficient & $0.327 * *$ & $0.351 * *$ \\
\hline & $p$ value & $<0.001$ & $<0.001$ \\
\hline \multirow[t]{2}{*}{ Eye pain coronavirus } & Correlation coefficient & $0.392 * *$ & $\mathbf{0 . 3 8 9} * *$ \\
\hline & $p$ value & $<0.001$ & $<0.001$ \\
\hline \multirow[t]{2}{*}{ Sore eye coronavirus } & Correlation coefficient & $0.219 *$ & 0.175* \\
\hline & $p$ value & 0.012 & 0.047 \\
\hline \multirow[t]{2}{*}{ Burning eye } & Correlation coefficient & -0.035 & -0.085 \\
\hline & $p$ value & 0.692 & 0.334 \\
\hline \multirow[t]{2}{*}{ Watery eyes } & Correlation coefficient & -0.008 & 0.009 \\
\hline & $p$ value & 0.931 & 0.919 \\
\hline \multirow[t]{2}{*}{ Epiphora } & Correlation coefficient & $-0.305^{* *}$ & $-0.343 * *$ \\
\hline & $p$ value & $<0.001$ & $<0.001$ \\
\hline \multirow[t]{2}{*}{ Protective face mask } & Correlation coefficient & $0.543 * *$ & $0.510 * *$ \\
\hline & $p$ value & $<0.001$ & $<0.001$ \\
\hline
\end{tabular}

with non-normal distribution were expressed as median (interquartile range). Spearman's rank-order correlation coefficient was used for the analyses of correlations. A p value of less than 0.05 was considered statistically significant.

\section{Results}

The statistical results of the investigated data are shown separately in Tables 2, 3, 4, 5, 6, and 7. Also, the first five keywords that generate the highest RSV values in the aforementioned five countries and worldwide are demonstrated in Fig. 1.

In brief, the daily RSVs of the keyword of 'coronavirus eye' correlated with the number of daily
COVID-19 new cases and new deaths in the United Kingdom, Spain, Italy, Turkey, and worldwide and correlated with the number of daily COVID-19 new cases in Germany (Tables 2, 3, 4, 5, 6, and 7) (Fig. 2). The daily RSVs of the keyword of "coronavirus eye symptoms' correlated with the number of daily COVID-19 new cases and new deaths in Spain and Italy. Also, the daily RSVs of this keyword correlated with the number of daily COVID-19 new cases in the United Kingdom and Turkey and correlated with the number of daily COVID-19 new deaths worldwide (Tables 2, 3, 4, 5, and 7). The daily RSVs of the keyword of 'conjunctivitis' correlated with the number of daily COVID-19 new cases and new deaths in Italy and correlated with the number of daily COVID19 new cases in Turkey (Tables 5 and 7). The daily 


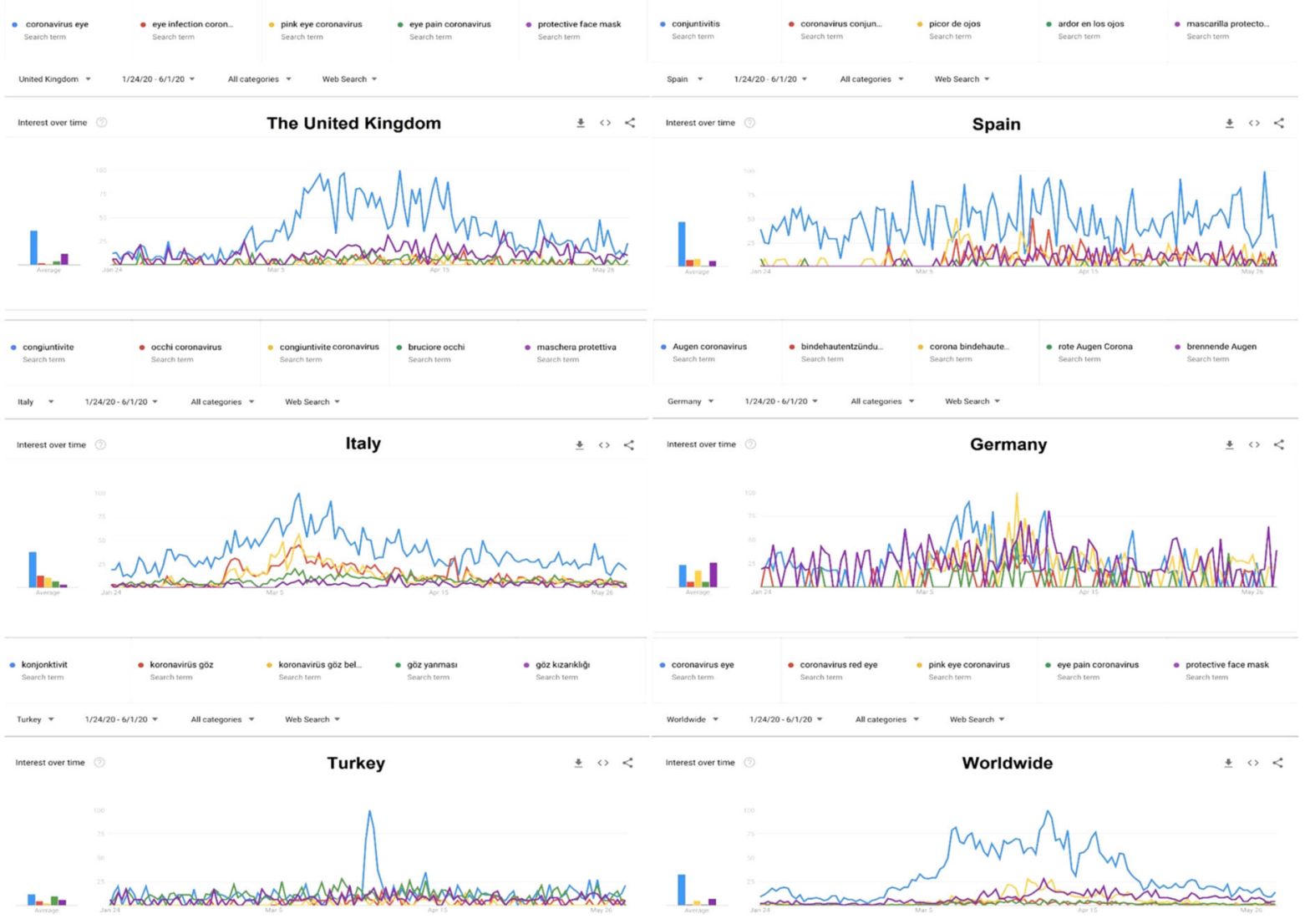

Fig. 1 The graphs of the first five keywords which generate the highest RSV values in the United Kingdom, Spain, Italy, Germany, Turkey, and worldwide between January 24 and June 1, 2020, in Google Trends

RSVs of the keyword of 'red eye' correlated with the number of daily COVID-19 new cases and new deaths in Turkey and correlated with the number of daily COVID-19 new deaths in Italy (Tables 5 and 7). The daily RSVs of the keyword of 'coronavirus red eye' correlated with the number of daily COVID-19 new cases and new deaths in Germany and worldwide (Tables 2 and 6). The daily RSVs of the keyword of 'pink eye coronavirus' and 'eye pain coronavirus' correlated with the number of daily COVID-19 new cases and new deaths in the United Kingdom and worldwide (Tables 2 and 3). The daily RSVs of the keyword of 'burning eye' correlated with the number of daily COVID-19 new cases and new deaths in Spain, Italy, Turkey, and worldwide and correlated with the number of daily COVID-19 new cases in Germany (Tables 2, 4, 5, 6, and 7). The daily RSVs of the keyword of 'protective face mask' correlated with the number of daily COVID-19 new cases and new deaths in the United Kingdom, Spain, Italy, Germany, Turkey, and worldwide (Tables 2, 3, 4, 5, 6, and 7).

In addition, there were no correlations in the daily RSVs of keywords of 'eye infection', 'watery eyes', and 'epiphora' with the number of daily COVID-19 new cases and new deaths in the United Kingdom, Spain, Italy, Germany, Turkey, and worldwide (Tables 2, 3, 4, 5, 6, and 7).

\section{Discussion}

It is already known that contact of infectious body fluids with the mucosal membrane in the mouth, nose, and eye is the main route for the transmission of severe 

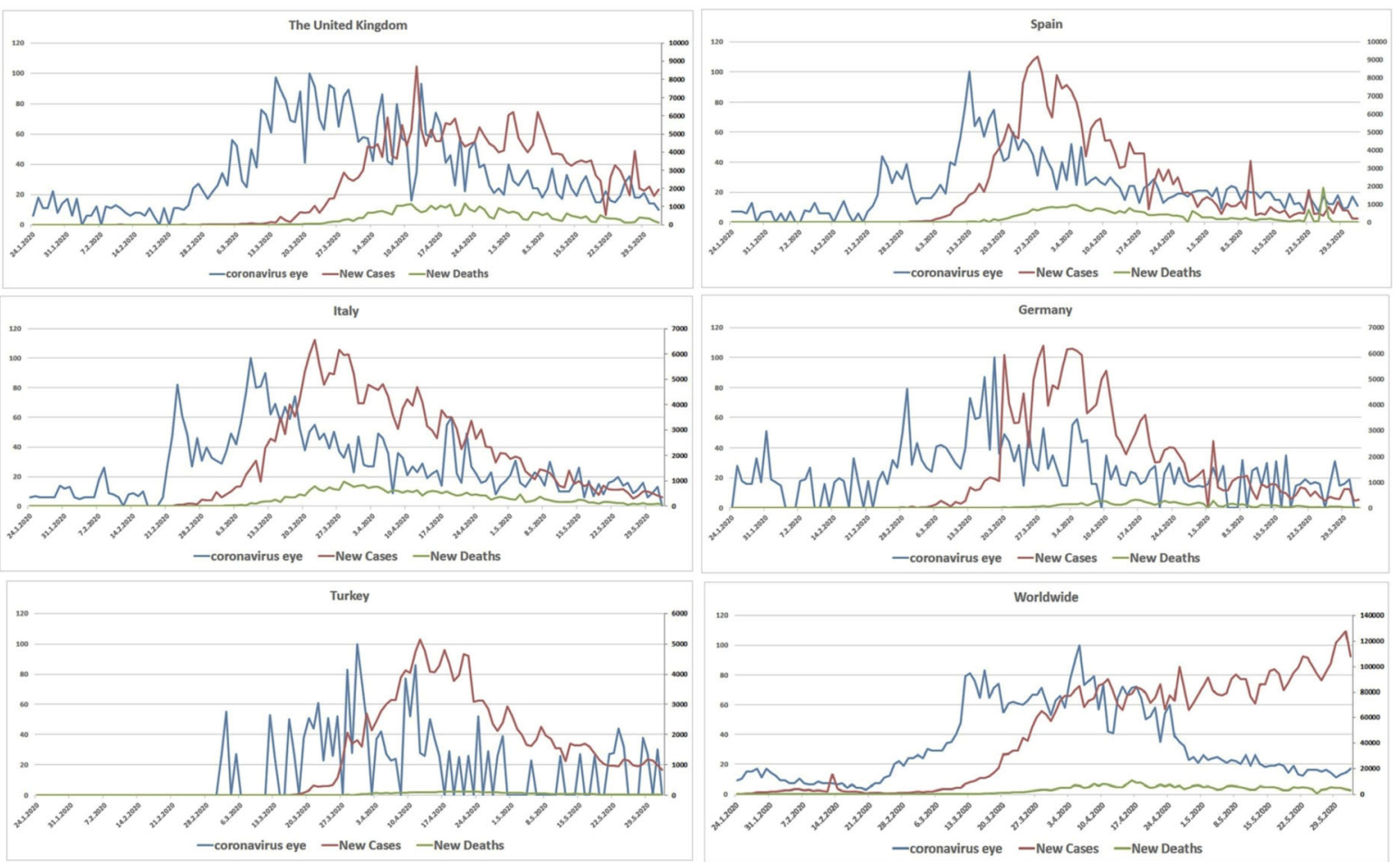

Fig. 2 The RSVs of the keyword of 'coronavirus eye' and the number of COVID-19 new cases and new deaths in the United Kingdom, Spain, Italy, Germany, Turkey, and worldwide between January 24 and June 1, 2020

acute respiratory syndrome coronavirus (SARS-CoV) [19].

In February 2020, Lu et al. have commented that inhalation of droplets may not be the only pathway for the transmission of the pathogen of COVID-19 which is named as severe acute respiratory syndrome coronavirus 2 (SARS-CoV-2) [20]. The authors have drawn attention that direct or indirect contamination of the conjunctival epithelium with infectious droplets may be another route for the transmission of COVID19. For this reason, it was advised people that touching eyes is a risky habit at this moment. Also, it was recommended to doctors, nurses, healthcare members, and other workers who are working in close contact with people that they should wear eye protection masks or face masks to protect themselves [21].

In March 2020, in the study of Wu et al., the authors have reported that 12 of 38 patients with clinically confirmed COVID-19 had ocular findings such as epiphora, increased secretions, conjunctivitis, chemosis, or conjunctival hyperemia [7]. But 2 of 12 COVID-19 patients with ocular findings had positive results for SARS-CoV-2 on RT-PCR from conjunctival swabs. In these patients, one patient had epiphora as the initial complaining of COVID-19. On these outcomes, they have concluded that COVID-19 may transmit via ocular surface but there is low evidence.

In April 2020, Daruich et al. have published a case report of a patient with conjunctivitis as the first sign of COVID-19 which was detected by telemedicine consultation [6]. The patient had no systemic symptoms but the general condition of the patient deteriorated in a short time following the detection of conjunctival hyperemia in his eye. The diagnosis of the COVID-19 was confirmed after positive RT-PCR for SARS-CoV-2, and ocular findings were regressed after eleven days of treatment. On the other hand, Chen et al. have reported a case report of a confirmed COVID-19 patient with bilateral redness in his eyes about 2 weeks after the onset of symptoms of sore throat and diarrhea in April 2020 [8]. Moreover, RTPCR result of the conjunctival swab specimens was positive for SARS-CoV-2. The authors have commented that conjunctivitis as an ocular finding of COVID-19 may not occur only in the early period of 
Table 4 The correlation of the RSVs of the keywords with COVID-19 new cases and new deaths in Spain
**Correlation is significant at the 0.01 level (2-tailed)

*Correlation is significant at the 0.05 level (2-tailed)

Bold results: Statistically significant results

\begin{tabular}{|c|c|c|c|}
\hline Keywords (Spain) & & New cases & New deaths \\
\hline \multirow[t]{2}{*}{ Coronavirus eye symptoms } & Correlation coefficient & $0.488 * *$ & $0.338 * *$ \\
\hline & $p$ value & $<0.001$ & $<0.001$ \\
\hline \multirow[t]{2}{*}{ Itchy eyes } & Correlation coefficient & $\mathbf{0 . 5 3 7} * *$ & $0.399 * *$ \\
\hline & $p$ value & $<0.001$ & $<0.001$ \\
\hline \multirow[t]{2}{*}{ Itchy eyes coronavirus } & Correlation coefficient & $0.522 * *$ & $0.363^{* *}$ \\
\hline & $p$ value & $<0.001$ & $<0.001$ \\
\hline \multirow[t]{2}{*}{ Conjunctivitis } & Correlation coefficient & 0.067 & 0.061 \\
\hline & $p$ value & 0.448 & 0.492 \\
\hline \multirow[t]{2}{*}{ Coronavirus conjunctivitis } & Correlation coefficient & $0.726 * *$ & $0.718 * *$ \\
\hline & $p$ value & $<0.001$ & $<0.001$ \\
\hline \multirow[t]{2}{*}{ Eye infection } & Correlation coefficient & -0.096 & -0.069 \\
\hline & $p$ value & 0.279 & 0.437 \\
\hline \multirow[t]{2}{*}{ Red eye } & Correlation coefficient & 0.059 & 0.123 \\
\hline & $p$ value & 0.507 & 0.164 \\
\hline \multirow[t]{2}{*}{ Watery eyes } & Correlation coefficient & -0.103 & -0.088 \\
\hline & $p$ value & 0.243 & 0.317 \\
\hline \multirow[t]{2}{*}{ Burning eyes } & Correlation coefficient & 0.182* & 0.195* \\
\hline & $p$ value & 0.038 & 0.026 \\
\hline \multirow[t]{2}{*}{ Epiphora } & Correlation coefficient & $-0.255^{* *}$ & $-0.241 * *$ \\
\hline & $p$ value & 0.003 & 0.006 \\
\hline \multirow[t]{2}{*}{ Protective face mask } & Correlation coefficient & $0.484 * *$ & $0.481 * *$ \\
\hline & $p$ value & $<0.001$ & $<0.001$ \\
\hline
\end{tabular}

the disease. Due to these similar publications, the place of the eye in COVID-19 was a matter of debate and eye immunity began to be questioned. [22, 23] Also, due to the news in the mass media, societies may have been attracted and awareness of the ocular signs of the COVID-19 may have been raised. [6, 8, 24-26] Therefore, the public interest of online searches on ocular signs of COVID-19 has increased.

Human-to-human transmission of SARS-CoV-2 has caused governments to give orders such as stayat-home and social distancing. As well, lockdown has been carried out in many countries. Thus, outpatient visits have been reduced as much as possible and this unprecedented circumstance has caused people to search their complaints, symptoms, and get medical information mostly from internet search engines.

Moreover, many websites provide a wide range of opportunities for researchers to collect data on different topics and this new trend brought out infodemiology in the era of technology. Infodemiology is a new search field that includes analyzing internet data streams to inform about changes that can be foreseen in public health, especially during outbreaks [27]. In the last decade, there has been an increase in internetbased studies in the field of health information. The rate of internet searches has given researchers useful information about the course of the diseases, especially about infectious diseases. For instance, the association between influenza occurrence and influenza-related search terms has been investigated in the study of Polgreen et al. by using Yahoo! internet search engine and it was demonstrated that internet search activity for influenza predicted an increase in cultures positive for influenza 1-3 weeks before conventional reporting systems do [28].

Thus, evaluating internet-based information in unprecedented outbreaks may be a supplemental method to predict the course of infectious diseases. This kind of investigation may give clues for additional symptoms or may help to detect the changes in infectious disease activity. In this period, countless websites have given information about the COVID-19 
Table 5 The correlation of the RSVs of the keywords with COVID-19 new cases and new deaths in Italy
**Correlation is significant at the 0.01 level (2-tailed)

*Correlation is significant at the 0.05 level (2-tailed)

Bold results: Statistically significant results

\begin{tabular}{|c|c|c|c|}
\hline \multicolumn{2}{|l|}{ Keywords (Italy) } & \multirow{2}{*}{$\begin{array}{r}\text { New cases } \\
0.594 * *\end{array}$} & \multirow{2}{*}{$\frac{\text { New deaths }}{0.480 * *}$} \\
\hline Coronavirus eye & Correlation coefficient & & \\
\hline & $p$ value & $<0.001$ & $<0.001$ \\
\hline \multirow[t]{2}{*}{ Coronavirus eye symptoms } & Correlation coefficient & $0.435 * *$ & $0.321 * *$ \\
\hline & $p$ value & $<0.001$ & $<0.001$ \\
\hline \multirow[t]{2}{*}{ Conjunctivitis } & Correlation coefficient & $0.408 * *$ & $0.274 * *$ \\
\hline & $p$ value & $<0.001$ & 0.002 \\
\hline \multirow[t]{2}{*}{ Coronavirus conjunctivitis } & Correlation coefficient & $\mathbf{0 . 5 8 0} * *$ & $\mathbf{0 . 4 5 8} * *$ \\
\hline & $p$ value & $<0.001$ & $<0.001$ \\
\hline \multirow[t]{2}{*}{ Coronavirus conjunctivitis symptoms } & Correlation coefficient & $\mathbf{0 . 4 1 8}^{* *}$ & $0.309 * *$ \\
\hline & $p$ value & $<0.001$ & $<0.001$ \\
\hline \multirow[t]{2}{*}{ Eye infection } & Correlation coefficient & 0.001 & 0.033 \\
\hline & $p$ value & 0.991 & 0.711 \\
\hline \multirow[t]{2}{*}{ Red eye } & Correlation coefficient & 0.172 & $0.195 *$ \\
\hline & $p$ value & 0.050 & 0.027 \\
\hline \multirow[t]{2}{*}{ Burning eyes } & Correlation coefficient & $0.565 * *$ & $0.503 * *$ \\
\hline & $p$ value & $<0.001$ & $<0.001$ \\
\hline \multirow[t]{2}{*}{ Watery eyes } & Correlation coefficient & -0.048 & -0.111 \\
\hline & $p$ value & 0.585 & 0.207 \\
\hline \multirow[t]{2}{*}{ Epiphora } & Correlation coefficient & -0.124 & -0.098 \\
\hline & $p$ value & 0.160 & 0.268 \\
\hline \multirow[t]{2}{*}{ Protective face mask } & Correlation coefficient & $0.456 * *$ & $0.446^{* *}$ \\
\hline & $p$ value & $<0.001$ & $<0.001$ \\
\hline
\end{tabular}

pandemic. Mostly, people use internet search engines to get medical information. In addition, numerous medical journals have opened access publicly to supply updated information about the COVID-19 pandemic. For instance, the RSVs of the keyword of 'conjunctivitis' peaked on March 29-30, 2020, in Turkey [29]. At the same date, news drawing attention to the relation between conjunctivitis and COVID-19 was shared on the websites of three of the most widely read newspapers in Turkey [24-26]. This example may reflect the effect of mass media on the search activity of internet users. Indeed, there was a lot of traffic in the frequency of searching COVID-19related keywords on the internet, globally. Presumably, this big data may reflect the COVID-19 activity. Internet sources such as GT provide free access to the data of users' online activities and search queries. GT which is a very useful and free-to-access tool of
Google supplies information about the search volumes of a particular subject or word in a certain region within a certain time interval. Thus, GT is a prominent internet data source for researchers during the COVID-19 pandemic. Several studies have recently been published to evaluate the relationship of different symptoms or diseases with COVID-19 using GT analysis [11-15].

Loss-of-smell-related and otolaryngology-related search volumes obtained by GT have been investigated during the COVID-19 pandemic in Italy, Spain, the United Kingdom, the United States, Germany, France, Iran, and The Netherlands and it was stated in these studies that there is a correlation between the RSVs of anosmia and COVID-19 in these countries [11-13]. As well, GT analyses of lung diseases and gastrointestinal symptoms related to the COVID-19 have also been evaluated in different countries and it 
Table 6 The correlation of the RSVs of the keywords with COVID-19 new cases and new deaths in Germany

\begin{tabular}{|c|c|c|c|}
\hline Keywords (Germany) & & New cases & New deaths \\
\hline \multirow[t]{2}{*}{ Coronavirus eye } & Correlation coefficient & $0.225 *$ & -0.107 \\
\hline & $p$ value & 0.010 & 0.227 \\
\hline \multirow[t]{2}{*}{ Conjunctivitis } & Correlation coefficient & $-0.620 * *$ & $-0.795 * *$ \\
\hline & $p$ value & $<0.001$ & $<0.001$ \\
\hline \multirow[t]{2}{*}{ Conjunctivitis coronavirus } & Correlation coefficient & $0.243 * *$ & -0.045 \\
\hline & $p$ value & 0.005 & 0.610 \\
\hline \multirow[t]{2}{*}{ Corona conjunctivitis } & Correlation coefficient & $0.740 * *$ & $\mathbf{0 . 5 3 8} * *$ \\
\hline & $p$ value & $<0.001$ & $<0.001$ \\
\hline \multirow[t]{2}{*}{ Red eye } & Correlation coefficient & -0.094 & -0.118 \\
\hline & $p$ value & 0.286 & 0.181 \\
\hline \multirow[t]{2}{*}{ Red eye corona } & Correlation coefficient & $0.408 * *$ & $0.229 * *$ \\
\hline & $p$ value & $<0.001$ & 0.009 \\
\hline \multirow[t]{2}{*}{ Eye infection } & Correlation coefficient & 0.090 & 0.103 \\
\hline & $p$ value & 0.308 & 0.241 \\
\hline \multirow[t]{2}{*}{ Burning eyes } & Correlation coefficient & $0.197 *$ & 0.019 \\
\hline & $p$ value & 0.025 & 0.827 \\
\hline \multirow[t]{2}{*}{ Watery eyes } & Correlation coefficient & -0.109 & -0.164 \\
\hline & $p$ value & 0.219 & 0.062 \\
\hline \multirow[t]{2}{*}{ Epiphora } & Correlation coefficient & -0.132 & -0.088 \\
\hline & $p$ value & 0.135 & 0.321 \\
\hline \multirow[t]{2}{*}{ Protective face mask } & Correlation coefficient & $0.790 * *$ & $\mathrm{o.885}^{* *}$ \\
\hline & $p$ value & $<0.001$ & $<0.001$ \\
\hline
\end{tabular}

was demonstrated that some search queries of associated keywords or terms have increased and some of them have decreased during the COVID-19 pandemic $[14,15]$.

To the best of our knowledge, the present study is a novel study in ophthalmology that aimed to investigate ocular-symptoms-related searches during the COVID-19 pandemic using GT. The preliminary outcomes of this study showed that the most RSVs of the investigated ocular-symptoms-related keywords were correlated with the COVID-19 new cases and new deaths in the United Kingdom, Spain, Italy, Germany, Turkey, and worldwide. We should state that the data obtained from GT does not contain the actual number of search activity. Instead, it represents the relative volume of the search terms rather than quantitative information. Due to this limitation, we could not compare the RSVs of the selected keywords among the countries. But, it has drawn our attention that the correlation of the investigated data was higher in Italy. In addition, one of the deeply affected countries in Europe at the beginning of the COVID19 pandemic was Italy. Also, the present study has some other limitations. This infodemiological study contains the data of users who have access to the internet. Therefore, it may not be claimed that it represents the entire society in the aforementioned countries. In addition, users may have searched some keywords due to seasonal allergic ocular symptoms and the RSVs of these keywords may be part of our data. As well, users without ocular symptoms may have influenced by media news about ocular signs of COVID-19 and may have wanted to search some terms on the internet. 
Table 7 The correlation of the RSVs of the keywords with COVID-19 new cases and new deaths in Turkey

B*Correlation is significant
at the 0.01 level (2-tailed)
*Correlation is significant at
the 0.05 level (2-tailed)
Bold results: Statistically
significant results

\section{Conclusion}

Nevertheless, the outcomes of our study contribute to the literature on both COVID-19 and infodemiology. It may provide a different perspective on COVID-19 and give an opinion on public interest to internet search activity of ocular-symptoms-related keywords during the lockdown. Also, this study can inspire some researchers and lead to newer and more comprehensive studies in this field. GT analysis seems to need to be further developed. The less inaccurate the researched data will ensure that the predictions for the diseases are more consistent. The exclusion of the bias mentioned above by developing GT software will make the researches in this field more valuable.

Author contributions EM contributed to concept and design and drafted the manuscript, EM and GDM were involved in data acquisition and data analysis/interpretation, EM, GDM, and SB contributed to statistical analysis, and EM, GDM, RO, SB, and MO were involved in critical revision of manuscript and supervision. All authors read and approved the final manuscript.

Funding There is no funding.
Data availability The datasets used and/or analyzed during the current study are available from the corresponding author on reasonable request.

\section{Declarations}

Conflict of interest The authors declare that they have no competing interests.

Ethics approval The Necmettin Erbakan University Ethics Committee approved this is a retrospective study as an audit study and gave it the following reference number: 2020/2768.

\section{References}

1. World Health Organization, WHO Director - General's Remarks at the Media Briefing on 2019-nCoV on 11 February 2020; 2020 https://www.who.int/dg/speeches/ detail/who-director-general-s-remarks-at-the-mediabriefing-on-2019-ncov-on-11-february-2020

2. WHO Novel coronavirus (2019-nCoV) situation report - 51 (11 March 2020). Geneva: World Health Organization; 2020 https://www.who.int/docs/default-source/ coronaviruse/situation-reports/20200311-sitrep-51-covid19.pdf

3. World Health Organization. (2020). Coronavirus disease 2019 (COVID-19): situation report, 133. World Health Organization. https://apps.who.int/iris/handle/10665/332281 
4. WHO Director-General's opening remarks at the media briefing on COVID-19 - 13 March 2020; https://www.who. $\mathrm{int} / \mathrm{dg} /$ speeches/detail/who-director-general-s-openingremarks-at-the-mission-briefing-on-covid-19-13-march2020

5. Chen N, Zhou M, Dong X, Qu J, Gong F, Han Y, Qiu Y, Wang J, Liu Y, Wei Y et al (2020) Epidemiological and clinical characteristics of 99 cases of 2019 novel coronavirus pneumonia in Wuhan, China: a descriptive study. Lancet (London, England) 395(10223):507-513

6. Daruich A, Martin D, Bremond-Gignac D (2020) Ocular manifestation as first sign of Coronavirus disease 2019 (COVID-19): interest of telemedicine during the pandemic context. J Fr Ophtalmol 43(5):389-391. https://doi.org/10. 1016/j.jfo.2020.04.002

7. Wu P, Duan F, Luo C et al (2020) Characteristics of ocular findings of patients with Coronavirus disease 2019 (COVID-19) in Hubei Province China. JAMA Ophthalmol 138(5):575-578. https://doi.org/10.1001/jamaophthalmol. 2020.1291

8. Chen L, Liu M, Zhang Z et al (2020) Ocular manifestations of a hospitalised patient with confirmed 2019 novel coronavirus disease. Br J Ophthalmol 104(6):748-751. https:// doi.org/10.1136/bjophthalmol-2020-316304

9. Search Engine Market Share; https://www.netmarketshare. com/search-engine-market-share. Accessed 22 Jun 2020

10. Mavragani A, Ochoa G (2019) Google trends in infodemiology and infoveillance: methodology framework. JMIR Public Health Surveill 5(2):e13439. https://doi.org/10.2196/ 13439

11. Walker A, Hopkins C, Surda P (2020) Use of google trends to investigate loss-of-smell-related searches during the COVID-19 outbreak. Int Forum Allergy Rhinol 10(7):839-847. https://doi.org/10.1002/alr.22580

12. Pier MM, Pasick LJ, Benito DA, Alnouri G, Sataloff RT (2020) Otolaryngology-related google search trends during the COVID-19 pandemic. Am J Otolaryngol 41(6):102615. https://doi.org/10.1016/j.amjoto.2020.102615

13. Panuganti BA, Jafari A, MacDonald B, DeConde AS (2020) Predicting COVID-19 incidence using anosmia and other COVID-19 symptomatology: preliminary analysis using google and twitter. Otolaryngol Head Neck Surg 163(3):491-497. https://doi.org/10.1177/0194599820932128

14. Barbosa MT, Morais-Almeida M, Sousa CS, Bousquet J (2020) The, "Big Five" lung diseases in CoViD-19 pandemic - a google trends analysis. Pulmonology S2531-0437(20):30142-30152. https://doi.org/10.1016/j. pulmoe. 2020.06 .008

15. Rajan A, Sharaf R, Brown RS, Sharaiha RZ, Lebwohl B, Mahadev S (2020) Association of search query interest in gastrointestinal symptoms with COVID-19 diagnosis in the United States: infodemiology study. JMIR Public Health Surveill 6(3):e19354. https://doi.org/10.2196/19354

16. Spiteri G, Fielding J, Diercke M et al (2020) First cases of coronavirus disease 2019 (COVID-19) in the WHO European region, 24 January to 21 February 2020. Euro Surveill
25(9):2000178. https://doi.org/10.2807/1560-7917.ES . 2020.25.9.2000178

17. Google Trends. Google Trends. https://trends.google.com/ trends, Accessed date: 23 June 2020.

18. WHO Coronavirus Disease (COVID-19) Dashboard; https://covid19.who.int/

19. Peiris JS, Yuen KY, Osterhaus AD, Stöhr K (2003) The severe acute respiratory syndrome. $N$ Engl J Med 349(25):2431-2441. https://doi.org/10.1056/ NEJMra032498

20. Lu CW, Liu XF, Jia ZF (2020) 2019-nCoV transmission through the ocular surface must not be ignored. Lancet 395(10224):e39. https://doi.org/10.1016/S01406736(20)30313-5

21. Li JO, Lam DSC, Chen Y, Ting DSW (2020) Novel Coronavirus disease 2019 (COVID-19): the importance of recognising possible early ocular manifestation and using protective eyewear. Br J Ophthalmol 104(3):297-298. https://doi.org/10.1136/bjophthalmol-2020-315994

22. Neri P, Pichi F (2020) COVID-19 and the eye immunity: lesson learned from the past and possible new therapeutic insights. Int Ophthalmol 40(5):1057-1060. https://doi.org/ 10.1007/s10792-020-01389-2

23. Neri P, Lamperti M, Pichi F (2020) SARS-COV-2 and eye immunity: the lesson was learned but we are not done yet Brainstorming on possible pathophysiology inspired by ocular models. Int Ophthalmol 40(8):1879-1883. https:// doi.org/10.1007/s10792-020-01495-1

24. Son dakika haberler: Konjonktivit corona belirtisi mi? Corona virüsü belirtileri nelerdir, ne zaman başlar? https:// www.sabah.com.tr/saglik/2020/03/30/30-hastadan-1-indecorona-virusu-yeni-belirtisi-tespit-edildi-son-dakikacorona-virusu-belirtileri-nelerdir-iste-koronavirus-yenibelirtiler

25. Konjonktivit nedir? Konjonktivit Corona virüsü belirtisi mi? https://www.hurriyet.com.tr/galeri-konjonktivit-nedirkonjonktivit-corona-virusu-belirtisi-mi-41480892

26. Konjonktivit nedir? Corona virüste yeni belirti bulundu. https://www.ntv.com.tr/saglik/konjonktivit-nedir-coronaviruste-yeni-belirti-bulundu,8zokeDk7G0qhhnbKbcqo0A

27. Eysenbach G (2009) Infodemiology and infoveillance: framework for an emerging set of public health informatics methods to analyze search, communication and publication behavior on the Internet. J Med Internet Res 11(1):e11. https://doi.org/10.2196/jmir.1157

28. Polgreen PM, Chen Y, Pennock DM, Nelson FD (2008) Using internet searches for influenza surveillance. Clin Infect Dis 47(11):1443-1448. https://doi.org/10.1086/ 593098

29. Google Trends. https://trends.google.com/trends/ explore?date $=2020-01-24 \% 202020-06-01 \&$ geo $=$ TR\&q= konjonktivit Accessed date: 23 Jun 2020.

Publisher's Note Springer Nature remains neutral with regard to jurisdictional claims in published maps and institutional affiliations. 